\title{
Abraão e Aventureiro: pensando o turismo de camping na Ilha Grande - RJ
}

\section{Roberta Mociaro Zanatta*}

Resumo: As praias do Aventureiro e do Abraão, situadas na Ilha Grande - Angra dos Reis (RJ), são atualmente destinos turísticos muito valorizados e recebem turistas nacionais e internacionais. Desde 1994, com a implosão do Instituto Penal Cândido Mendes, que ficava na praia de Dois Rios, próxima ao Abraão, o turismo tornou-se a principal atividade econômica da Ilha, ocorrendo, no entanto, de formas bem variadas nas diferentes praias. Assim, a praia do Aventureiro, do lado oceânico e com um número relativamente baixo de moradores, cerca de 150, tem como meio de hospedagem campings, aluguel de quartos e casas (as próprias casas dos moradores). Já a praia do Abraão, voltada para o continente e tida como a porta de entrada e capital da Ilha Grande, com cerca de 3.000 habitantes, conta com um sofisticado aparato turístico, que inclui pousadas, campings, restaurantes e ciber cafés. Investigando os diversos atores sociais envolvidos nesses dois contextos, busco desvendar: de um lado, as percepções referentes às escolhas e estratégias relacionadas especificamente ao turismo de camping, tanto da parte das populações locais quanto da parte dos visitantes; e de outro lado, as vivências e implicações desse turismo de camping na implementação do turismo e conseqüente desenvolvimento local na Ilha Grande.

Palavras-chave: Ilha Grande; Turismo; Desenvolvimento Local; Antropologia do Turismo

\begin{abstract}
Ilha Grande (Big Island), situated in Rio de Janeiro, is currently one of the most important tourist destinations in Brazil. Some of Its beaches such as Aventureiro and Abraão are very popular among national and international tourists. After the destruction of the Criminal Institute Cândido Mendes, in 1994, tourism became the island's main economic activity. The old prison was located in Dois Rios, a beach near Abraão - the main village in the island. The tourism works in different ways in each beach. In Aventureiro's beach, positioned in the oceanic side of the island, there are a relatively low number of inhabitants, about 150, but there are as half of lodging campings, rental rooms and houses for rent (the proper houses of the inhabitants). On the other hand Abraão's beach, situated directed toward the continent, has about 3,000 inhabitants. It counts on sophisticated tourist apparatus, that includes settled, campings, restaurants and internet access in coffee shops. By analyzing many social actors involved in these two contexts, each of those being either Aventureiro's beach and Abrão's beach, I search to unmask the following: from one side, the perceptions of the choices and strategies related specifically to the camping tourism, as much as
\end{abstract}

* Roberta Mociaro Zanatta é mestranda do Programa de Pós-Graduação em Ciências Sociais da Universidade do Estado do Rio de Janeiro (PPCIS/UERJ).

INTRATEXTOS, Rio de Janeiro, Número Especial 01, pp.123-133, 2010 
part of the local populations life and also the part of the visitors side. Beyond the experiences and implications of its camping tourism on the implementation of the tourism and consequence to the local development in Ilha Grande.

Keywords: Ilha Grande; Tourism; Local development; Tourism Anthropology

Entre 2002 e 2007 fiz parte da equipe de pesquisa de Rosane Prado na Ilha Grande e em 2006 defendi minha monografia de graduação A morte dos Guapuruvus: uma reflexão sobre identidade local e turismo na Ilha Grande. Atualmente ainda pesquiso na Ilha, nas praias do Abraão e Aventureiro para elaboração de dissertação de mestrado ${ }^{1}$.

A metodologia de trabalho aplicada se baseia em dados obtidos durante períodos de trabalho de campo, dentro de uma perspectiva de caráter antropológico, e fundamentada em métodos qualitativos, abrangendo observação participante, entrevistas, análise de recortes de jornal; bem como em leituras e discussões de textos referentes ao objeto em questão.

Vale ressaltar que, após pesquisa e leitura de artigos, dissertações e teses sobre a Ilha Grande, e mais especificamente sobre o Abraão e o Aventureiro, pude observar que existe muita coisa produzida, mas não com enfoque específico no turismo de camping. No caso do Aventureiro, como se trata de uma área relativamente pequena, cerca de $1 \mathrm{~km}$ de extensão de faixa de areia, e o meio de hospedagem predominante é o camping, que se estende praticamente por todas as casas da vila, os trabalhos ali produzidos tratam evidentemente do tema, mas não focam necessariamente nele. Já no caso do Abraão, também encontrei alguns trabalhos produzidos, mas como lá existe uma grande diversidade de opções de meios de hospedagem e de entretenimento em geral, os trabalhos não tratam especificamente do tema do turismo de camping. Neste sentido, um dos objetivos desta pesquisa é traçar um pequeno panorama do turismo de camping no Abraão e no Aventureiro e dos momentos pelos quais passou desde que o turismo como um todo ganhou força na Ilha Grande.

A Ilha Grande, situada no Estado do Rio de Janeiro, é atualmente considerada um grande pólo turístico, que recebe turistas de todo o Brasil e do mundo. Na Ilha encontramos desde mochileiros ${ }^{2}$ até milionários que lá vão passear com suas lanchas e iates; existem muitas opções de entretenimento e diversão para variados gostos e possibilidades de 
recursos financeiros. Desde 1994, quando foi implodido o Instituto Penal Candido Mendes, que ficava na Praia de Dois Rios, próxima ao Abraão - porta de entrada da Ilha Grande - o turismo tornou-se sua principal atividade econômica. A Ilha possui 106 praias $^{3}$, entre as quais pelo menos 13 abrigam comunidades, que podem variar em número de habitantes, tipos de ocupação e de atividades de trabalho, mas que em maior ou menor grau têm o turismo como uma atividade rentável.

Neste trabalho, foco o turismo de camping nas praias de Abraão e Aventureiro. Essa escolha se deve ao fato de serem praias com tipos de ocupação díspares, o Abraão contando com cerca de 3.000 moradores $^{4}$, com um grande aparato turístico, repleto de pousadas, restaurantes, agências de passeios turísticos de escunas, cyber cafés, e toda uma gama de possibilidades voltada para o turista. A praia é visitada por turistas de variados perfis e faixas etárias. As construções são uma marca do lugar que constantemente tem obras em andamento 5 . Já a Praia do Aventureiro, com um número relativamente baixo de moradores, cerca de 150, não dispõe de lojas, agências de passeios de barco e pousadas. Tem como meio de hospedagem campings, aluguel de quartos e casas (em geral as próprias casas dos moradores). Servem refeições nos campings, ou em cerca de 5 bares a beira-mar, sendo que em períodos de baixa temporada só funcionam 3, e as atrações naturais são todas visitadas através de caminhadas, trilhas e passeios de barco. $\mathrm{O}$ principal público que frequienta a praia é de surfistas, amantes da prática do camping e de caminhadas em trilhas e pessoas a procura de um “paraíso natural”. Recentemente, sua população teve de enfrentar batalhas judiciais para conseguir ter direito a ficar no Aventureiro e a explorar o seu potencial turístico de forma sustentável, pois em 1981 uma lei estadual transformou o local em Reserva Biológica, categoria de Unidade de Conservação que proíbe até mesmo a presença de pessoas, a não ser para fins educativos, ou científicos. ${ }^{6}$

As praias do Abraão e do Aventureiro abrigam toda uma diversidade de situações que podem ser pensadas a partir do atual cenário turístico que vem tomando conta da Ilha Grande há cerca de 15 anos, desde a desativação do Instituto Penal Cândido Mendes. Desta forma, busco investigar em ambas as praias os diversos atores sociais ali envolvidos com o turismo de camping, suas percepções, escolhas e estratégias; o que caracteriza a trajetória deste tipo de turismo até a sua configuração atual.

INTRATEXTOS, Rio de Janeiro, Número Especial 01, pp.123-133, 2010 
Para tanto, comparo dois momentos distintos a propósito da mudança de perspectiva dos moradores e comerciantes locais sobre o turismo de camping nas praias do Abraão e Aventureiro, que acompanhei ao longo dos 7 anos em que venho realizando pesquisa, como parte da equipe da professora Rosane Prado na Ilha Grande. Em um primeiro momento, pesquisando no Abraão, entre os anos de 2002 e $2005^{7}$, pude notar que a visão predominante entre uma parte dos moradores e donos de estabelecimentos comerciais locais em relação ao turista que viaja acampando com uma mochila nas costas era pejorativa, identificada com falta de recursos, os "duristas", como muitos deles os chamavam.

O público dos campings freqüentemente se enquadra no estigma de 'duristas', alvo das enfáticas reclamações acerca das 'bagunças' e da sujeira deixada nas praias e nas trilhas do Abraão. Essa atribuição é alimentada pela tendência dos preços dos campings serem mais baixos, sendo uma opção para visitantes com recursos limitados. Existem campings 'de época', 'não oficiais', como é o caso dos quintais das casas situadas na Vila, parte do território do Abraão cujo regulamento pró́be a construção de novos edifícios e pousadas. De certo modo, desconhecer o perfil de um público que surge 'não se sabe de onde' durante épocas de férias, ânimos aquecidos e exacerbação de disputas de todo tipo - todos esses acontecimentos que marcam o verão - alimentam a desconfiança tanto de nativos quanto de pousadeiros. São freqüentes relatos de histórias 'estranhas', que acontecem nos campings, como de 'bandidos escondidos', ou casos de tráfico de drogas, principalmente naqueles localizados nas encostas, afastados da área mais movimentada do Abraão. (MALBOUISSON, 2004, p.53-54)

Vale ressaltar que o texto acima citado de Malbouisson foi escrito em 2004, período em que este tipo de visão era freqüente entre moradores e comerciantes locais do Abraão. $\mathrm{Na}$ época, o que era referido como "turismo de qualidade" por certos seguimentos estava associado a ter recursos e poder ficar "bem instalado". Já em um segundo momento, em 2008, quando retorno ao Abraão para realizar trabalho de campo para a presente pesquisa, me dou conta de que o discurso predominante hoje entre os mesmos comerciantes é o do “turismo de qualidade", mas agora aplicado tanto a pousadas de luxo como a campings. É de se notar como esse turismo é equacionado a um maior gasto financeiro por parte dos turistas. Em entrevista realizada com um turista que já acampou no Abraão e no Aventureiro, este cita sua experiência no Abraão em oposição ao Aventureiro:

Lá no Abraão o camping é mais caro, o preço atualmente varia entre uns 15,00 e 20,00 reais por dia, mas em feriado e Ano Novo só com pacote,

INTRATEXTOS, Rio de Janeiro, Número Especial 01, pp.123-133, 2010 
sai uns 150, 200,00 reais. O melhor camping do Abraão é o Santanas, tem área de jogos coberta, o banheiro é ótimo, tudo limpinho, mas também é o mais caro. Aqui no Aventureiro ainda é mais barato acampar. (João Paulo, 24 anos) ${ }^{8}$

Ao retornar ao Abraão, o que mais me chamou a atenção foi a mudança de atitude por parte dos referidos moradores e comerciantes, que ao invés de continuarem vendo o turismo de camping como marginal, passaram a adotar, em relação a ele também, o discurso do "turismo de qualidade". Logo que desembarquei no Abraão perguntei para algumas pessoas se sabiam em que camping poderia ficar. Um rapaz, morador sazonal ${ }^{9}$ do Abraão, que veio no mesmo barco que eu, me indicou alguns campings, mas logo ressaltou: "Se você quiser vai encontrar camping até de cinco reais, mas não vale a pena. Lá é mais barato mas você vai ter dor de cabeça, não tem segurança e às vezes nem banheiro, no final sai mais caro! Vale a pena pagar um pouco mais e ter mais tranquiilidade, segurança e conforto". Agradeci e segui adiante, repeti a pergunta para mais uma pessoa que passava e a um comerciante, que me deram respostas bem parecidas com a primeira. $\mathrm{O}$ modo como me alertaram parecia querer dizer: "Você quer ter a sua imagem associada a este tipo de camping?” Em minha leitura, este episódio somado a mais algumas conversas com antigos conhecidos como o fotógrafo André Ilha, também morador sazonal da Ilha, me fizeram refletir sobre essa mudança de discurso em direção à idéia desse tal "turismo de qualidade" e o que exatamente seria esse turismo. Segundo André: “(...) agora o custo de vida por aqui aumentou muito. (...) Já tem umas guaritas para o lado da Praia Preta, aqui está ficando com cara de Parque”. Esta fala a meu ver caracteriza essa nova fase do Abraão que parece especificar mais o significado de "turismo de qualidade" na correlação com: aumento de preços, melhoria de estrutura e delimitação de leis e regras destacando a condição de "Parque Estadual" como atrativo que deve ser valorizado e restringido a um menor número de visitantes, mas ao mesmo tempo com um maior gasto per captos.

Apoiando a promoção desse "turismo de qualidade", a prefeitura de Angra dos Reis adotou a campanha "Camping Legal", ou seja, os campings que forem devidamente cadastrados e autorizados recebem uma faixa em sua entrada com o slogan da campanha: “Camping Legal - Prefeitura de Angra dos Reis".

Já no Aventureiro o cenário turístico se caracteriza de modo diferente, pois praticamente o único tipo de turismo lá realizado sempre foi e continua sendo o de 
camping. Os moradores dessa praia se mostram satisfeitos e receptivos e têm lucro com essa atividade que é vista por eles como uma alternativa ao trabalho na pesca e roça. Atualmente, o turismo, mais do que uma alternativa as atividades tradicionalmente praticadas pelos moradores da Ilha Grande - no caso do Aventureiro -, é a única opção para seus moradores, pois, segundo as leis ambientais vigentes lá, não se pode caçar, pescar, retirar madeira ou plantas da mata e a pesca também sofre restrições, mesmo a permanência da população local nesta praia é polêmica, visto que a categoria de Reserva Biológica, a ela atribuída na década de 80 , permite somente a presença humana com fins científicos. No momento está em discussão a possibilidade de re-categorização da faixa que se estende da Praia do Aventureiro até a Praia do Demo, mantendo como Reserva Biológica a Praia de Sul e de Leste.

Ao contrário do discurso de alguns moradores e donos de comércio do Abraão, que em um primeiro momento argumentavam que este tipo de turista não traz grandes recursos, o povo do Aventureiro sempre "simpatizou" com esse visitante que passou a trazer uma nova fonte de renda para o local. Sven Wunder, que pesquisou a comunidade em 1999, há 10 anos atrás, já apontava que:

A hipótese corriqueira de que 'os mochileiros não geram renda para a Ilha' é rejeitada: embora gastem pouco por pessoa, em lugares onde o número de visitantes é grande, a renda do turismo é alta, se comparada com qualquer atividade produtiva tradicional, o que reduz consideravelmente a pobreza local. $\mathrm{O}$ volume de dinheiro movimentado com o turismo na região foi utilizado para construção de residências, compra de bens duráveis e para o tempo de lazer adicional. (WUNDER, 2006, p.135-136)

O que pude observar até o presente momento, a partir das idas a campo realizadas e da leitura de trabalhos já produzidos sobre essa comunidade (CATÃO, 2004; 2009; COSTA, 2004; 2008; 2009; HAGINO, 2009; WUNDER, 2006), é que ali também se pode falar de dois momentos distintos do turismo de camping: um primeiro no qual essa modalidade não era percebida como atividade comercial, mas como um tipo de camaradagem que rendia algum tipo de vantagem para ambos - anfitriões e visitantes (parafraseando o título do livro Hosts and guests, um marco nos estudos sobre turismo, publicado na década de 70). Era comum a troca de favores, como ajudar a puxar a rede de pesca de moradores locais, varrer quintais ou deixar pertences como roupas, pranchas e 
alimentos, para em troca acampar em seus quintais. Neste sentido destaco a entrevista que Costa (2008) realizou com um dos filhos de Luis, dono do camping de maior destaque do Aventureiro, ao indagar sobre quando começaram a chegar os turistas:

Tomei até um susto, de repente. Vinha gente pra cá, ficava no nosso camping, mas a gente não cobrava nada não. Porque nunca veio ninguém pra cá. Aí acampava aí, saía, aí às vezes deixava comida, que sobrava, deixava pra nós, roupa, aí começou a deixar a prancha, praticamente nossas pranchas era tudo que os caras deixavam aí. Aí cada vez foi vindo mais gente, vindo mais gente, aí começamos a cobrar, a cobrar, aí começou com a galera, que invadiu, né? Acabou nisso. (João Paulo)

Nesse relato percebe-se que os moradores não tinham então a visão de que a atividade turística poderia ser rentável para eles a ponto de substituir a atividade pesqueira, sua principal fonte de renda na época. Nesse primeiro momento os preços cobrados eram mínimos e a renda vinha por meio do grande volume de visitantes, o que trouxe impactos ambientais sazonais: “(...) a qualidade das águas da baía é comprometida durante os picos de visitação, mas, a partir de observações de moradores e turistas, ocorre uma recuperação durante a baixa temporada, com exceção talvez da área portuária do Abraão.” (WUNDER, 2006, p.144). Mesmo os danos à natureza sendo condicionados a períodos de maior visitação, o excesso de turistas no Aventureiro culminou na proibição da atividade turistítica ao longo do ano de 2006, quando a liminar que permitia o acampamento foi cassada e os turistas que acampavam durante o carnaval foram retirados de lá pela polícia. ${ }^{10}$ A partir desse episódio, a promotora Patrícia Gabai instaurou um inquérito junto ao Ministério Público em defesa do povo do Aventureiro. Uma série de reportagens do jornal O Globo sobre a Ilha Grande publicada em março de 2006 destaca o incidente:

A Praia do Aventureiro faz parte da Reserva Biológica Estadual da Praia do Sul, onde a presença do homem só seria permitida para fins científicos ou de educação ambiental. O problema é que, segundo o MP, os caiçaras habitam o local há pelo menos três séculos e a unidade de proteção ambiental foi criada em 1981. (O Globo, 13/03/2006)

No final de 2006, após várias reuniões e audiências com o Ministério Público, que envolveram representates locais, professores e pesquisadores envolvidos com a comunidade, Ongs e "amigos" do Aventureiro, a volta da atividade turistica foi permitida, mas com restrições quanto ao número de pessoas e regras de permanência no local. Além do considerável aumento do gasto per captos dos vistantes, mais uma vez reforçando a idéia

INTRATEXTOS, Rio de Janeiro, Número Especial 01, pp.123-133, 2010 
de um "turismo de qualidade" ligado a um número menor de turistas que gastem mais. A título de ilustração, o valor gasto comparativamente há 5 anos atrás é bem maior do que hoje. A média da diária de um camping tanto no Abraão como no Aventureiro era de 5,00 reais, hoje é de 20,00 reais. No caso do Aventureiro, o preço da passagem de barco também aumentou de 15,00 reais por pessoa para 40,00 reais.

Assim, considero este evento - o fechamento e re-abertura dos campings no Aventureiro - como um marco que define o início de um segundo momento, no qual seus moradores já estão plenamente conscientes de que a atividade turística é um negócio para eles e que terão que negociar e se adaptar às novas configurações que se colocam como condição para a continuidade desta atividade turística em sua comunidade.

O objetivo deste trabalho é investigar os diversos atores sociais envolvidos nesses dois contextos, desvendando: de um lado, as percepções referentes às escolhas e estratégias relacionadas especificamente ao turismo de camping, tanto da parte das populações locais quanto da parte dos visitantes; e de outro lado, as vivências e implicações desse turismo de camping na implementação do turismo e conseqüente desenvolvimento local na Ilha Grande.

Considero que os dois casos aqui investigados - Abraão e Aventureiro - fazem pensar sobre diferentes possibilidades de um mesmo turismo, o de camping. São praias de uma mesma Ilha, porém com perfis de visitantes quase que opostos. No Abraão, a porta de entrada da Ilha, a 50 minutos de Conceição de Jacareí de saveiro ou de catamarã de Angra dos Reis, é o local de mais fácil acesso da Ilha com transporte diário em diversos horários para o continente. Nesta praia existe uma grande movimentação de pessoas, barzinhos, festas, passeios de barco diários, mercado, posto médico, corpo de bombeiros, polícia, toda uma estrutura que remete a uma mini-cidade. Já no Aventureiro as pessoas que vão para lá querem ou encontram quase que o oposto do Abraão. Para se chegar na Praia do Aventureiro é necessário se credenciar no posto da TurisAngra, pois existe um número prédeterminado de pessoas que podem ir para lá, cerca de 540. Os barcos não saem o ano todo, pois nos meses de inverno muitas vezes o mar não permite a passagem $^{11}$ e mesmo em períodos de verão nem sempre o número mínimo de pessoas para que saia um barco é alcançado. O tempo estimado de viagem é de duas horas e meia a 3 horas, sendo que pelo menos 40 minutos desse tempo é de navegação em mar aberto. Enfim, ao se chegar ao 
Aventureiro o desembarque é feito em botes ${ }^{12}$, pois o cais está em obra a meses e a prefeitura de Angra dos Reis não entrega a obra concluída, ou em um cais, quando não estava em obras, que fica a cerca de $1 \mathrm{~km}$ da praia. A eletricidade ainda não chegou por conta do difícil acesso e das leis ambientais que proíbem seu uso, os moradores recorrem então a geradores movidos a óleo diesel que funcionam até cerca de $23 \mathrm{~h}$. O sossego é grande, as festas chegam a ser no máximo uma espécie de luau, com eventuais violões, zabumba e algum outro instrumento de percussão. As pessoas ficam na praia basicamente o dia todo e não há preocupações com usar tênis, sapato de salto, secar os cabelos ou usar roupas "arrumadas", como é no Abraão. Muitos dos turistas entrevistados que acampam no Aventureiro alegam não ir para o Abraão para não se preocuparem com tais questões. A sensação de estar no Aventureiro é a de estar longe de tudo, em um paraíso isolado pela natureza. Enfim, mesmo com tantas diferenças, ambos os lugares, cada um com uma proposta de turismo diferente, podem atender a um mesmo tipo de turismo que é feito por pessoas com objetivos e motivações bem diferentes, mas que em última análise fazem parte de uma mesma cultura - a cultura de camping.

\section{REFERÊNCIAS BIBLIOGRÁFICAS}

CATÃO, Helena. Redefinindo territórios: preservação e transformação no Aventureiro Ilha Grande-RJ. Dissertação de mestrado. Rio de Janeiro: CPDA/ UFRuralRJ. 2004.

CATÃO, Helena; COSTA, Gustavo Villela; PRADO, Rosane. Praia do Aventureiro: um caso sui generis de gestão local do turismo. Rio de Janeiro, 2009 (no prelo).

COSTA, Gustavo Villela Lima da. A população do Aventureiro e a Reserva Biológica Estadual da Praia do Sul: Conflitos e disputas sob a tutela ambiental. Dissertação de mestrado. Rio de Janeiro: PPGAS/ Museu Nacional/ UFRJ, 2004

. O Aventureiro, Ilha Grande-RJ: uma análise de mudança social. Rio de Janeiro: PPGAS/ Museu Nacional/ UFRJ, 2008.

CLIFFORD, James. Sobre a autoridade etnográfica. In: GONÇALVES, J. Reginaldo (org.). A experiência etnográfica. Rio de Janeiro: EDUFRJ, 1998.

BARTH, F. O guru, o iniciador e outras variações antropológicas. (org. Tomke Lask). Rio de Janeiro: Contra Capa, 2000.

INTRATEXTOS, Rio de Janeiro, Número Especial 01, pp.123-133, 2010 
BAUMAN, Zygmunt. Turistas e vagabundos: os heróis e as vítimas da pós-modernidade. In: O mal-estar da pós-modernidade. Rio de Janeiro: Jorge Zahar, 1998.

CHAMBERS, Erve (Ed.). Tourism and culture: an applied perspective. Albany: State University of New York, 1997.

GEERTZ, Clifford. Do ponto de vista dos nativos: a natureza do conhecimento antropológico. In: O saber local. Petrópolis: Vozes, 1998.

GRABURN, Nelson. Secular ritual: a general theory of tourism. In: SMITH, Valene L. \& BRENT, Maryann (orgs.). Hosts and guests revisited: tourism issues of the 21st century. Nova York: Cognizant Com. Corporation, 2001.

GRÜNEWALD, Rodrigo. Turismo e etnicidade. Horizontes Antropológicos - Turismo, $\mathrm{n}^{\mathrm{o}}$ 20. Porto Alegre: UFRGS, 2003.

HAGINO, Cora Hisae da Silva. O conflito sócio-ambiental no processo de recategorização da Reserva Biológica da Praia do Sul, Ilha Grande, Angra dos Reis-RJ: a Praia do Aventureiro em disputa. Dissertação de mestrado. Rio de Janeiro: PPGSD/UFF, 2009.

MALBOUISSON, Augusto Brandão. Construções do Paraíso: Arquitetura e questões sociais no Abraão - Ilha Grande (RJ). Monografia de graduação em Ciências Sociais. Rio de Janeiro: UERJ, 2004.

PRADO, Rosane. As espécies exóticas somos nós: Reflexão a propósito do ecoturismo na Ilha Grande. Horizontes Antropológicos - Turismo, no 20, ano 9, Porto Alegre: UFRGS, 2003.

Caracterização das vilas e povoados. In: Estudos para o Plano de Manejo do Parque Estadual da Ilha Grande. Rio de Janeiro: Instituto Estadual de Florestas, mímeo, 2008.

PRADO, Rosane M. \& CATÃO, Helena. Fronteiras do manejo: embate entre concepções num universo de unidades de conservação. Porto Seguro: 26 ${ }^{\mathrm{a}}$. Reunião Brasileira de Antropologia, 2008.

SAHLINS, Marshall. O "pessimismo sentimental" e a experiência etnográfica: por que a cultura não é um "objeto" em via de extinção (parte I). Mana 3/2 (Estudos de Antropologia Social), abril/1997. Rio de Janeiro: PPGAS, Museu Nacional, UFRJ / Ed. Contracapa, 1997.

SANTOS, Myrian Sepulveda. Notas de Pesquisa: os Conflitos entre Natureza e Cultura na Implementação do EcoMuseu Ilha Grande. Rio de janeiro: no prelo, 2002.

. A construção da violência: o caso da Ilha Grande. In: PRADO, R. M. (org.). Ilha Grande: do sambaqui ao turismo. Rio de Janeiro: EdUERJ, 2006.

INTRATEXTOS, Rio de Janeiro, Número Especial 01, pp.123-133, 2010 
. Os Porões da República: As prisões da Ilha Grande (1894-1945). Rio de Janeiro: Garamond, 2009 (prelo).

SMITH, Valene (org.). Hosts and guests: the anthropology of tourism. $2^{\mathrm{a}}$ ed. Philadelphia: University of Pennsylvania Press, 1989.

STEIL, Carlos A. Antropologia do Turismo: Comunidade e Desterritorialização. Recife: $22^{\mathrm{a}} \mathrm{RBA}$, mimeo, 2004.

TENÓRIO, M. Cristina. Povoamento pré-histórico da Ilha Grande. In: PRADO, R. M. (org.) Ilha Grande: do sambaqui ao turismo. Rio de Janeiro: EdUERJ/Garamond, 2006.

URRY, John. O Olhar do Turista. São Paulo: Livros Studio Nobel Ltda, 1996.

VILAÇA, Maria Aparecida \& MAIA, Ângela de Azevedo. O povo do Aventureiro. In: PRADO, R. M. (org.). Ilha Grande: do sambaqui ao turismo. Rio de Janeiro: EdUERJ/Garamond, 2006.

WUNDER, Sven. Modelos de turismo, florestas e rendas locais. In: Ilha Grande: do sambaqui ao Turismo. Rio de Janeiro: Garamond/EDUERJ, 2006.

ZANATTA, Roberta Mociaro. A morte dos Guapuruvus: uma reflexão sobre identidade local e turismo na Ilha Grande. Monografia de graduação em Ciências Sociais. Rio de Janeiro: UERJ, 2006.

\footnotetext{
${ }^{1}$ Dissertação orientada pela professora Rosane Manhães Prado, PPCIS - UERJ.

${ }^{2}$ Mochileiros são turistas que viajam com mochilas nas costas e que muitas vezes se hospedam em campings, assim, estarão bastante em foco neste trabalho.

${ }^{3}$ Segundo o site: www.ilhagrande.org

${ }^{4}$ Em 2000, segundo o Censo IBGE eram 1481 moradores. Em 2008 estima-se, segundo informações do responsável pelos agentes comunitários do posto de saúde do Abraão, que existem cerca de 3.000 moradores.

${ }^{5}$ Para saber mais sobre o tema ver: "Construções do Paraíso: arquitetura e questões sociais no Abraão - Ilha Grande - RJ", Malbouisson, 2004.

${ }^{6}$ Para saber mais sobre o tema ver: Catão, Costa e Prado (2009).

${ }^{7}$ Entre os anos de 2002 a 2005 participei como bolsista de extensão do projeto de educação ambiental "Ilha Jovem", e posteriormente, até 2007, como bolsista de Iniciação Científica no projeto "Etnoecologia na Ilha Grande" da professora Rosane Manhães Prado.

${ }^{8}$ Entrevista realizada na Praia do Aventureiro em 01/11/2009.

${ }^{9}$ Denomino como morador sazonal pessoas que passam vários períodos do ano na Ilha Grande e que muitas vezes possuem casas alugadas.

${ }^{10}$ Reportagem sobre o tema publicada no jornal O Globo de 13/03/2006.

${ }^{11}$ Nos meses de junho e julho foram agendadas 5 idas a campo que não puderam ocorrer por não haver condições de navegação no mar.
}

INTRATEXTOS, Rio de Janeiro, Número Especial 01, pp.123-133, 2010 